\title{
Bubble-Film Network Structures of Radiation Synthesized Terpolymer Hydrogels
}

\author{
Jun SHAN, ${ }^{\dagger}$ Zhanjun LiU, ${ }^{*}$ Fanqin LI, ${ }^{* *}$ Guanghan Zuo, \\ Jun Ji, and Yanjun ZHANG \\ College of Chemical Engineering, Hefei University of Technology, Hefei, 230009 \\ * Department of Applied Chemistry, University of Science \& Technology of China, Hefei, 230026 \\ ** Center for Element \& Structure Analysis, University of Science \& Technology of China, Hefei, 230026
}

(Received December 3, 1996)

\begin{abstract}
Three series of terpolymer poly(AM-NaA-NTBA) hydrogels were synthesized by ${ }^{60}$ Co- $\gamma$ ray radiation polymerization in aqueous solutions. Their micro network structures observed by SEM displayed the bubble-film networks. However, with increase in $N$-tertiary butyl acrylamide (NTBA) units from $f_{\text {NTBA }}=0.052$ to 0.144 in terpolymer hydrogels, the lattice size of bubble-film network became larger and larger, a double layer structure between adjacent bubble films appeared in SEM micrographs of some terpolymers. The results are discussed from the existence of the steric hindrance effect of tertiary butyl group and the two opposite forces in the chain segments of terpolymers. The swelling kinetics of terpolymers at different acetone concentrations of aqueous solutions was investigated by examining the formation of bubble-film network terpolymer hydrogel.

KEY WORDS Hydrogel / Bubble-Film Network Structure / Swelling Kinetics / Terpolymer / Radiation Polymerization / Poly(acrylamide-sodium acrylate- $N$-tertiary butyl acrylamide) /
\end{abstract}

The hydrogel polymer is a kind of intelligent polymer material which can sharply sense the stimulus of circumstance and form the judgement and make the response. ${ }^{1,2}$ It is used for drug release and delivery, chemomechanical system and material separation. ${ }^{3-6}$

In our previous work, ${ }^{7-9}$ the micromorphologies of poly(acrylamide-sodium acrylate) bipolymer hydrogels and polyacrylamide and poly(sodium acrylate) homopolymer hydrogels synthesized by ${ }^{60} \mathrm{Co}-\gamma$ ray radiation polymerization were observed by SEM. The micromorphologies of several bipolymer hydrogels with different monomer molar ratios $\mathrm{AM} / \mathrm{NaA}$ displayed the bubble-film network structures, and nonhomogeneity of the inner fine structure of the hydrogel polymers were studied by the fractal and multifractal theory. The swelling kinetics of poly(acrylamide-sodium acrylate) hydrogel at different acetone concentrations of aqueous solution was studied. Swelling rates become lower and swelling equilibrium time longer with increase of acetone concentrations (which are still smaller than that at the volume phase transition point).

Here, three series of terpolymer poly(acrylamidesodium acrylate- $N$-tertiary butyl acrylamide) hydrogels were synthesized by the same method of ${ }^{60} \mathrm{Co}-\gamma$ ray radiation polymerization in aqueous solution, and micro network structures were observed by SEM. The influence of $N$-tertiary butyl acrylamide unit upon the bubble-film network structure of hydrogel terpolymers was investigated.

\section{EXPERIMENTAL}

\section{Materials}

Acrylamide (AM), acrylic acid (AA) monomers and $N, N^{\prime}$-methylene bisacrylamide (MBA) crosslinking agent were used. Sodium acrylate $(\mathrm{NaA})$ monomer was prepared from AA. Acrylonitrile (AN), cp, was purified by reduced pressure distillation. Tertiary butyl alcohol,

\footnotetext{
${ }^{\dagger}$ Author to whom correspondence is addressed.
}

$\mathrm{cp}$, was distilled before use. Concentrated sulfuric acid $(98 \%)$, AR, glacial acetic acid, AR, acetone, AR were used as supplied. The monomer $N$-tertiary butyl acrylamide (NTBA) was synthesized at this laboratory.

\section{Synthesis of Monomer N-tertiary Butyl Acrylamide (NTBA)}

The monomer NTBA was synthesized as follows ${ }^{10}$ :

$$
\begin{aligned}
& \mathrm{CH}_{2}=\mathrm{CH}-\mathrm{CN}+\left(\mathrm{H}_{3} \mathrm{C}\right)_{3} \mathrm{C}-\mathrm{OH} \underset{\mathrm{HOOCCH}_{3}<40^{\circ} \mathrm{C}}{\stackrel{\text { concd } \mathrm{H}_{2} \mathrm{SO}_{4}}{\longrightarrow}} \\
& \mathrm{CH}_{2}=\mathrm{CH}-\stackrel{\mathrm{O}}{\mathrm{C}}-\mathrm{NH}-\mathrm{C}\left(\mathrm{CH}_{3}\right)_{3}
\end{aligned}
$$

A white needle crystal product (NTBA) was obtained after recrystallizing from acetone and dried in vacuum. Its mp $125-126^{\circ} \mathrm{C}$.

\section{Synthesis of Terpolymer P(AM-NaA-NTBA) Hydrogels by Radiation Polymerization}

The method of synthesis was the same as reported previously. ${ }^{8}$ The total molar concentrations of two monomers $\mathrm{AM}$ and $\mathrm{NaA}$ and the mole fraction $f_{\mathrm{MBA}}$ of crosslinking agent MBA in every pregel solution were kept constant. The molar ratios of $\mathrm{AM} / \mathrm{NaA}$ were $9 / 1$, $8 / 2$, and $6 / 4$, respectively. The mole fraction $f_{\mathrm{NTBA}}$ of monomer NTBA was varied from 0.052 to 0.144 for I and II, and 0.101 for III. The absorbed dose and irradiation time were such that the conversion of all monomers would be nearly $100 \%$. Table I lists the

Table I. The compositions of the three P(AM-NaA-NTBA)

\begin{tabular}{|c|c|c|c|c|c|c|c|}
\hline \multirow[b]{2}{*}{ Hydrogel No. } & \multicolumn{3}{|c|}{ I } & \multicolumn{3}{|c|}{ II } & \multirow[t]{2}{*}{ III } \\
\hline & $\mathrm{I}_{1}$ & $\mathrm{I}_{2}$ & $\mathrm{I}_{3}$ & $\mathrm{II}_{1}$ & $\mathrm{II}_{2}$ & $\mathrm{II}_{3}$ & \\
\hline $\mathrm{AM} / \mathrm{NaA}$ & & $9 / 1$ & & & $8 / 2$ & & $6 / 4$ \\
\hline $\begin{array}{l}f_{\mathrm{NTBA}} \\
f_{\mathrm{MBA}}\end{array}$ & 0.053 & $\begin{array}{l}0.101 \\
0.012\end{array}$ & 0.144 & 0.052 & $\begin{array}{l}0.101 \\
0.012\end{array}$ & 0.144 & $\begin{array}{l}0.101 \\
0.012\end{array}$ \\
\hline
\end{tabular}
hydrogels 
compositions of the three terpolymer hydrogels.

SEM micrographs of hydrogel terpolymers were taken using a X-650 scanning electron microscope. The colorless and transparent hydrogels were dehydrated for 48 hours at room temperature in acetone solvent. The bars were dried under infrared damp for deleting absorption acetone. The samples were fractured carefully to reveal fresh cross sections and mounted on a stub using silver paint. The fresh cross sections of samples were coated with gold on a Eiko IB-3 ion coater. SEM micrographs are shown in Figures 1 and 2.

Measurement of Swelling Kinetics of Hydrogel $\mathrm{II}_{2}$

The barlike hydrogel $\mathrm{II}_{2}$ was carefully cut into many pieces about $5 \mathrm{~mm}$ long. Initial volume $\left(V_{0}\right)$ was measured. The samples were immersed in acetone-water solutions at acetone concentration of $0 \%, 10 \%, 30 \%$, $40 \%$, and $50 \%$ at $30^{\circ} \mathrm{C}$. The swelling ratio $\varphi_{\mathrm{i}}$ was determined from $\varphi_{\mathrm{i}}=V_{\mathrm{i}} / V_{0}$. The swelling kinetics of terpolymer hydrogel $\mathrm{II}_{2}$ is shown in Figure 3.

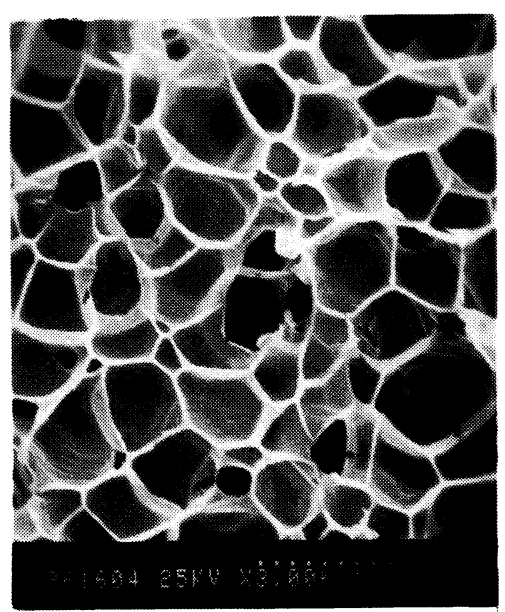

$\mathrm{I}_{1}$

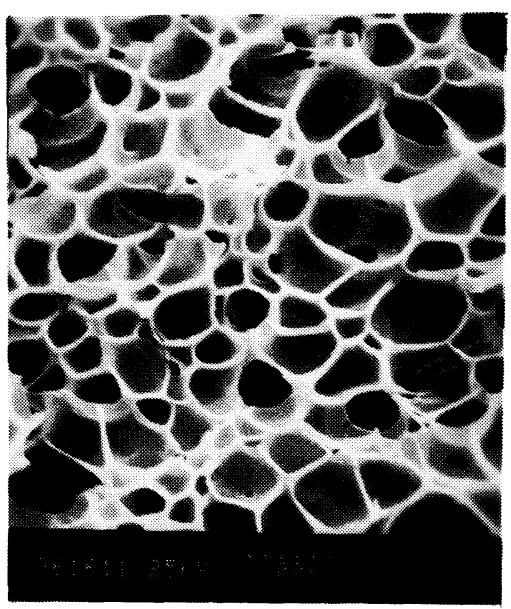

$\mathrm{II}_{1}$

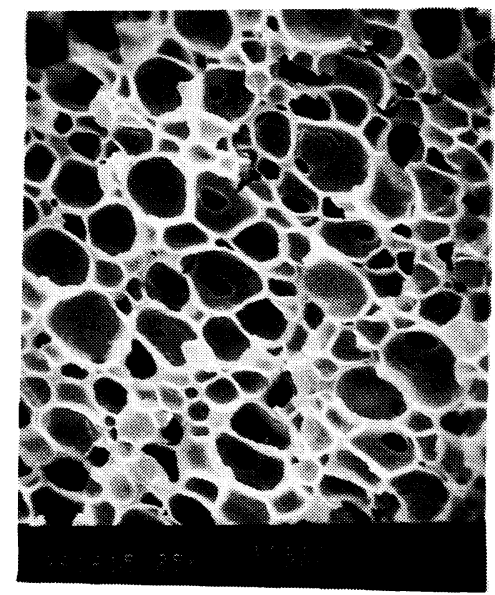

III

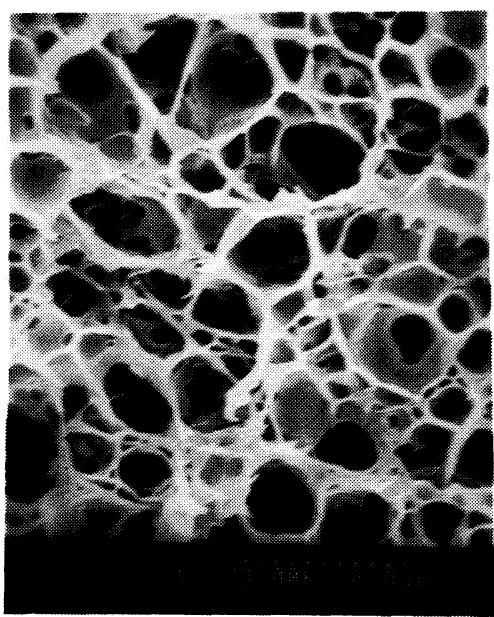

$\mathrm{I}_{2}$

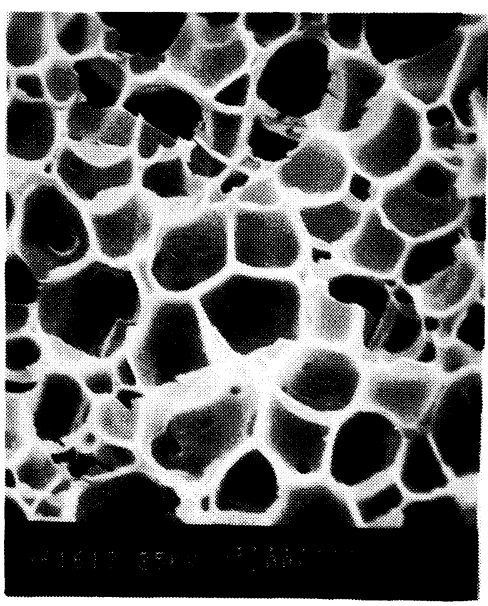

$\mathrm{II}_{2}$

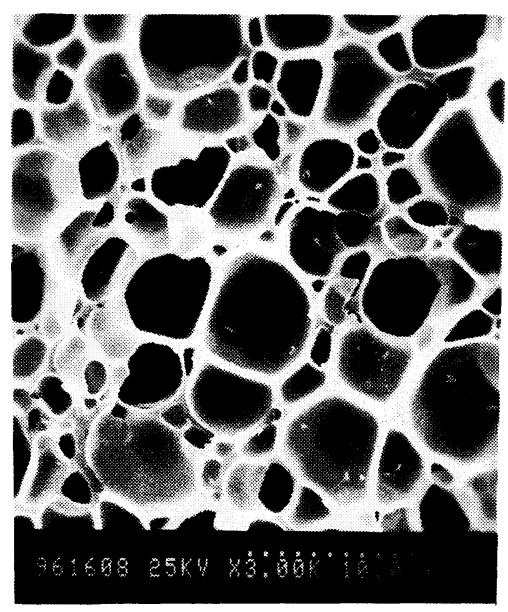

$\mathrm{I}_{3}$

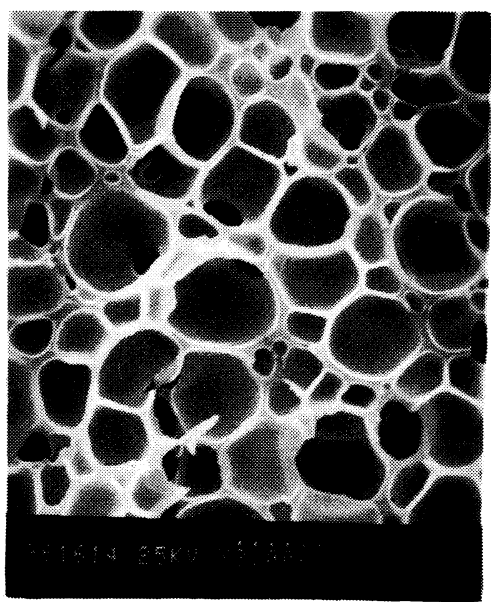

$\mathrm{II}_{3}$

Figure 1. SEM micrographs of hydrogel terpolymers: $\mathrm{I}_{1}, \mathrm{I}_{2}, \mathrm{I}_{3} ; \mathrm{II}_{1}$, $\mathrm{II}_{2}, \mathrm{II}_{3}$; III (magnification: $3.0 \mathrm{k}$ ). 


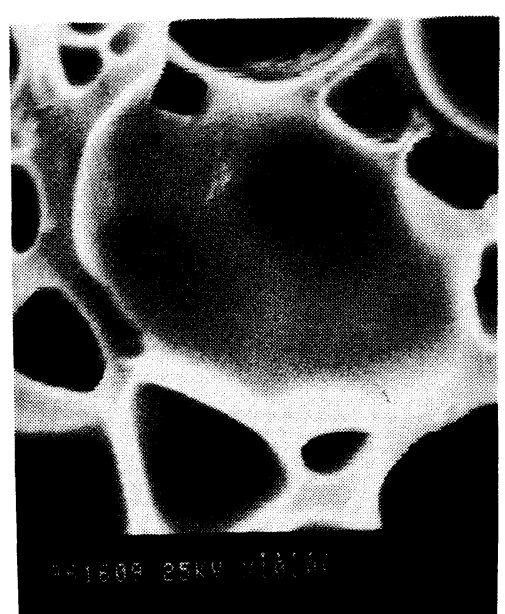

Figure 2. SEM micrograph of hydrogel terpolymer $I_{3}$ (magnification: $10.0 \mathrm{k})$.

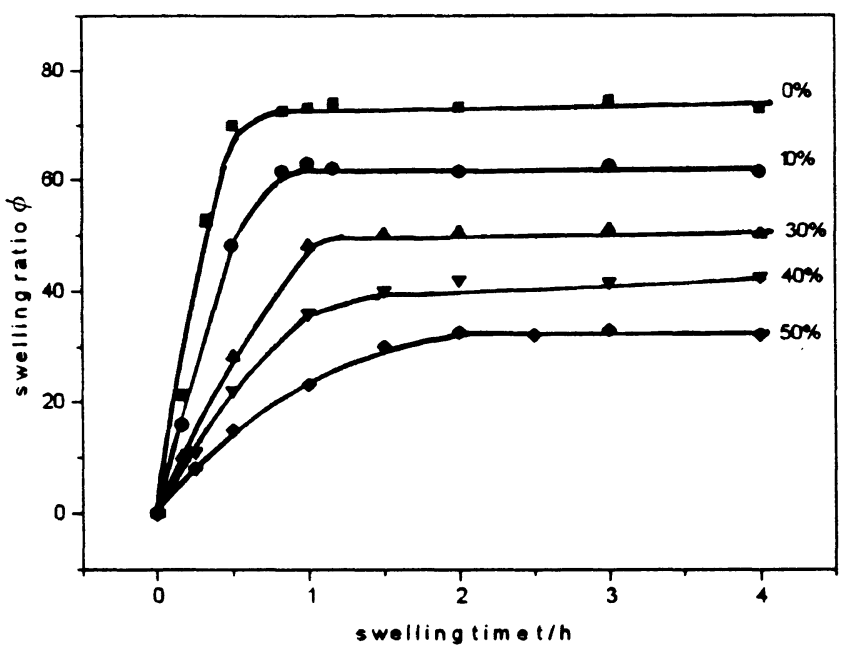

Figure 3. Curves of swelling rates of terpolymer hydrogel $\mathrm{II}_{2}$ at acetone concentrations of $0 \%, 10 \%, 30 \%, 40 \%$, and $50 \%$ in aqueous solution at $30^{\circ} \mathrm{C}$.

Table II. The lattice sizes of bubble-film network of three series of terpolymers

\begin{tabular}{ccccccccc}
\hline Hydrogel No. & $\mathrm{I}_{1}$ & $\mathrm{I}_{2}$ & $\mathrm{I}_{3}$ & $\mathrm{II}_{1}$ & $\mathrm{II}_{2}$ & $\mathrm{II}_{3}$ & $\mathrm{III}$ \\
\hline Size $/ \mu \mathrm{m}$ & $0.70-7.8$ & $0.70-8.3$ & $0.70-8.6$ & $0.70-6.4$ & $0.70-7.9$ & $0.70-8.6$ & $0.71-6.0$ & \\
\hline
\end{tabular}

\section{RESULTS AND DISCUSSION}

\section{Bubble-Film Network Structures of the Three P(AM-} NaA-NTBA) Hydrogel Terpolymers

In SEM micrographs of hydrogel terpolymers, it is evident that three terpolymers had bubble-film network structures. The bubble-film network structure is also present in $\mathrm{P}(\mathrm{AM}-\mathrm{NaA})$ hydrogel bipolymers. The formation of bubble-film network can be attributed to interactions between two opposite forces-the hydrogen bond attraction and electrostatic repulsion among the chain segments of bipolymers. In chain segments of terpolymer P(AM-NaA-NTBA), the steric hindrance of tertiary butyl group is bigger than that of bipolymers. Hence, a few chain segments with tertiary butyl groups weaken the hydrogen bond attraction between amide groups, and polymer-polymer affinity is lowered. The influence of the steric hindrance on the bubble-film network structure of terpolymers mainly shows the following:

(1) The lattice size of bubble-film network of terpolymer becomes larger with increase of NTBA units in terpolymers. Table II lists the lattice sizes of the bubblefilm networks of the three terpolymers.

(2) The double layer structure between the adjacent bubble films appears in the SEM micrographs of $\mathrm{I}_{3}$ and $\mathrm{II}_{3}$. This has not been observed in the P(AM-NaA) bipolymers.

Terpolymer $\mathrm{I}_{3}$ was magnified from $3.0 \mathrm{k}$ to $10.0 \mathrm{k}$ (shown in Figure 2). The bubble film seems much denser and semi-transparent and with no micro network or micro bubble film. The thickness of bubble film is shorter than $0.1 \mu \mathrm{m}$, and it is obvious that the bubble film is made up of many chain segments of terpolymer.
Influence of Bubble-Film Network Structure on Swelling Kinetics of Terpolymer Hydrogel $\mathrm{II}_{2}$

The swelling kinetics of terpolymer hydrogel $\mathrm{II}_{2}$ was similar to that of $\mathrm{P}(\mathrm{AM}-\mathrm{NaA})$ bipolymer hydrogel. The swelling rates of hydrogel $\mathrm{II}_{2}$ become slower with increase of acetone concentration from $0 \%$ to $50 \%$. The swelling ratios $\varphi$ at the swelling equilibrium become smaller, and swelling equilibrium time longer. In acetone-water solutions, only the water component is a good solvent for the hydrogels.

When the acetone concentrations are small, the hydrogel is swollen and its volume or swelling ratio is bigger and close to those of hydrogels in water. The chain segments of hydrogel polymer are extended. A large amount of free water and some acetone penetrate the hydrogels rapidly. Hence, the swelling rates are faster and swelling time shorter.

Increase in acetone concentration inhibits the swelling of hydrogels. This bubble film, similar to semipermeable membrane, hampers the permeation of water and acetone molecules in hydrogels. This makes the swelling rates lower and swelling equilibrium time longer.

\section{REFERENCES}

1. T. Tanaka, I. Nishio, and S. T. Sun, Science, 218, 467 (1982).

2. D. Nicoli, C. Young, and T. Tanaka, Macromolecules, 16, 887 (1983).

3. L. C. Dong, J. Controlled Release, 15, 141 (1991).

4. R. Yoshida, J. Biomaster. Sci., Polym. Educ., 3(2), 155 (1991).

5. C. M. Pai, J. Pharm. Sci., 81(6), 532 (1992).

6. Y. Osada and J. P. Gong, Prog. Polym. Sci., 13, 187 (1993).

7. J. Shan and Z. J. Liu, Chem. J. Chin. Univ., 16, 1467 (1995).

8. J. Shan, J. Chen, Z. J. Liu, and M. S. Zhang, Polym. J., 28, 886 (1996).

9. J. Shan and Z. J. Liu, Chem. Res. Appl., 7, 378 (1995).

10. K. Ulbrich and J. Kopecek, J. Polym. Sci., Polym. Symp., 66, 209 (1979). 